\title{
'Shaking the Conceptual Foundations,' Too: Integrating Research and Technology Support for the Next Generation of Information Service
}

\section{Chris Ferguson}

\begin{abstract}
Basic approaches to reference service have not altered in recent decades despite dramatic changes in user needs, customer service technologies, and transformations in other areas of the library. Rather than add more layers of experimental services that deplete resources and increase complexity, information service should be reconceived to include new partners in support of the use of technology while undertaking substantially new approaches to on-site and network-based information service. By reengineering organizations in ways that bring librarians and technologists together within a common service environment, information service agencies can more effectively meet our users' needs by moving more fully and flexibly into the network as changing circumstances warrant.
\end{abstract}

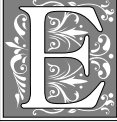
ight years ago, Jerry D. Campbell wrote a controversial article that was among the first of a wave of publications, listserv discussions, professional meetings, and "rethinking" institutes on the future of reference service. ${ }^{1}$ Nearly a decade later, his notions of (1) automating a large portion of reference service, with librarians engaged in new roles such as consumer analysis; (2) mapping new routes to new sources of information; and (3) putting users in touch with needed information within a largely electronic environment have become commonplace.
In the meantime, the world has changed dramatically, but fundamental approaches to academic library reference service have not. In the 1970s and 1980s, cataloging and acquisitions were infused with technology in ways that led to online catalogs, greater interinstitutional collaboration, and, ultimately, considerable reengineering of cataloging operations. In the 1980s and 1990s circulation and access services, driven by the rapid emergence of online catalogs, automated circulation systems, electronic reserve readings, and advances in document delivery and interlibrary loan (ILL), under-

Chris Ferguson, Director, Doheny Memorial Library, Information Services Division, at the University of Southern California; e-mail: cdf@usc.edu. The author gratefully acknowledges valuable comments on early drafts of this manuscript made by Phyllis Mirsky, UC San Diego; Beverly Lynch, UCLA; and Richard Werking, United States Naval Academy. An early version was presented to the 1999 ARL/UCLA Senior Fellows in August 1999. 
went fundamental changes in both the way they do business and the business they do, including multi-agency collaborations for the delivery of core services.

\section{The next generation of academic reference service must, in fact, broaden and deepen its presence in the network by reconceiving the parameters and nature of informa- tion service.}

Reference librarians have indeed made heroic accommodations for technology and major adaptations to new formats and communication media. Though somewhat dated, the sentiment of James Govan remains valid today:

The smoothness with which today's library staff have assimilated nationally networked cataloging, online searching, online local catalogs, microcomputers, local networking, compact discs, and the wide variety of other systems based on digitized information, while at the same time quietly schooling their patrons in the use of these systems, is a largely unrecognized miracle in American higher education over the past decade and a half. $^{2}$

Nevertheless, academic library reference service remains very much the same in terms of organizational structures, service philosophies and designs, and economic models. Reference service is the last frontier in libraries to engage in extensive interinstitutional collaboration for the delivery of basic services within digital environments, perhaps because it is the last to remain structured primarily around physical objects and the library as place. ${ }^{3}$

In recent years, many experiments in new approaches to reference service such as e-mail, videoconferencing, and cooperative approaches through the network have been undertaken in an earnest desire to meet users' changing needs. ${ }^{4} \mathrm{Al}-$ though these have been worthwhile attempts to move more fully into the network where users are going, reference service has a considerable way to go in order to meet user needs in an increasingly complex and digital environment. The next generation of academic reference service must, in fact, broaden and deepen its presence in the network by reconceiving the parameters and nature of information service. And in so doing, reference librarians must translate the core values of equity of access, personal service, and service tailored to individuals - the hallmarks of twentieth-century American libraries-in ways that retain their proximity and relevance for a generation of students and faculty who will have grown up with the Internet and the World Wide Web.

As it stands, though, academic library users have not taken to these new offerings in large numbers because reference services have not been adequately integrated within their information-seeking "space," either within the network or onsite within libraries and computing centers. Students and faculty still need to make a concerted effort to find these services, a prospect all the more difficult in cyberspace. Nor are these offerings typically associated with services academic library users frequently employ while communicating and researching, such as hardware and software support. Much less are they routinely available when and where they are most neededtwenty-four hours a day, seven days a week, and within an electronic research context. Janice Koyama expresses this more elegantly:

Cyberspace users are not confined by, or concerned with, building and reference desk hours nor the differences between the two. They defy categorization by a geographically based service provider that defines for itself its primary users. They prefer anonymity to in-person, over-the-desk delivery of reference service and feel free of the captive 
nature inherent sometimes in the personal interview controlled by the librarian. ${ }^{5}$

Moreover, reference librarians have not truly internalized or assimilated these new offerings into dynamic new service models but, rather, have conceived them largely as overlays or addons at the margins of existing service models-additional strata that require additional support when organizations should, instead, be reengineered to release resources for systemic change. Rather than struggle to maintain the status quo, librarians should invest heavily in the research and development of new tools, systems, and interagency affiliations that increase organizational agility and lead in uncharted new directions.

Much like earth at the center in the Ptolemaic cosmology of Antiquity and the Middle Ages, academic library reference service remains structured steadfastly around physical objects and the library as place. Users must come to the library and must seek the help of librarians to use it. At some visceral level, librarians know that a Copernican model is emerging wherein information and services flow to the user. This in turn is radically transforming the librarian-user relationship, yet librarians persist in the fading Ptolemaic model by overlaying new service after new service, much like epicycles in a Ptolemaic cosmology, without fundamentally altering underlying service models or reengineering organizations for a new way of looking at the universe. $^{6}$

Libraries are moving away from structures built up over decades (even centuries) around the print collection, on-campus classroom, and manageable growth rates in published information and, instead, are moving toward structures derived from digital communication, distributed learning, and an overwhelming surge in the creation and distribution of knowledge in multiple formats. Often this seems an inordinately slow and painful march that constrains creativity, deters meaningful action, and even lulls us into believing that these powerful trends can be resisted.

Meanwhile, funding agencies hold service providers more and more accountable, higher education enters an era of transformational change, and technology drives basic changes in the way that information seekers acquire and use information. ${ }^{7}$ We also witness the emergence of electronic scholarly communication systems, knowledge networks, commercial document delivery systems, and the electronic book. "Disintermediation," as some describe it, is in full motion-reference librarians being the intermediaries and the ones being "dissed." Conventional reference transactions and circulation statistics have begun a downward arc as students and faculty move more deeply into the Web, and the distance/distributed learning ship is about to leave port without information service providers aboard in substantial numbers. ${ }^{8}$

It is time for a different approach.

\section{Foundation for a New Approach to Information Service}

All too frequently, a vision of the future is derived from a comfortably realistic understanding of current resource constraints and organizational limits. Or one imagines fantastic, high-tech systems as a panacea, yet lacks the wherewithal to realize them. We should, instead, envision a desirable future for reference and related information and technology support services in a largely digital environment, then work backward to assess what resources and organizational structures are needed to realize that vision. In this way, we may be able to undertake an orderly transition from a largely print to a largely digital environment.

Of course, the future is highly flexible and all-embracing when viewed from the present, but the next generation of information service must, at minimum, recognize the convergence of information services and information technologies, 
address the implications of ubiquitous and portable computing, and provide a reinterpretation of our enduring service values for a new age.

\section{Convergence of Information Services and Technologies}

Less and less differentiation is being made in the minds of users between digital information and the way to get it. They are exhibiting less and less patience with multiple agencies responsible for what seems to be one process with little distinction among hardware, software, content, and the help needed to make it all work. This phenomenon may be most visible in an information commons, a concept proliferating rapidly among academic libraries that combines elements of libraries and computer user rooms. Donald Beagle aptly described how these new environments are breaking down boundaries among users and service providers alike, forcing reconceptualizations of how information and technology support services are provided along with the conventional divisions of labor behind them. ${ }^{9}$ In the University of Southern California's Leavey Library, the presence of electronic information resources, a full array of network navigation tools, and productivity software (including basic multimedia development tools) on each workstation in the information commons has driven the need since it opened in 1994 for a three-dimensional service model of navigation assistance, computing support, and research support. ${ }^{10}$

\section{Ubiquitous and Portable Computing}

The pressing challenge now is to support this kind of integrated information-seeking and service-support environment on a large scale and in remote locations as expectations for library, user room, desktop, and laptop workstations converge. User environments must be sustained where it is equally easy to find and use both print and digital information resources and where it is just as easy to receive reference or instruction assistance as it is to obtain help in support of soft- ware or hardware. Information retrieval support services must be as accessible as an online catalog, a digital object, a Web browser, or a software application is for someone roaming with a laptop computer on most campuses today. The extent to which this ideal is achieved is the extent to which our enduring service values are preserved in this new context.

\section{New Values for a New Age}

If equity of access, personalized service, and services tailored to individuals are enduring values that warrant reinterpretation for a new era, librarians must redouble their efforts to bring information services into the network in humane ways and on a human scale. ${ }^{11-12}$ This means providing a full range of support for users' technology and information needs to match the growing complexity of their work environment. It means finding ways to be available for real-time assistance wherever users may go and whenever they may go there-on-site or remote, 2 p.m. or 2 a.m., weekdays or weekends. $^{13}$

To make the technology work for all and in ways that meet individual needs, reference librarians must recognize that current approaches to information service are neither sustainable nor scalable to this massive new frontier. New service models, new roles for information professionals and the different kinds of organizations behind them, and new relationships with other agencies must be devised as we shift our collective gaze from our earth to their sun.

\section{Imagining a New Service Model}

It is tempting to think that the proliferation of digital technology and the emergence of the digital library will one day enable libraries to effect overnight a massive shift from print collections, traditional classrooms, and heavy reliance on fixed space for collections and services. We must, instead, recognize the need to maintain for the indefinite future a range of on-site services that embrace print collections even as we seek place and mean- 
ing in an emerging digital world. In an integrated service environment that fully supports contemporary uses of both print and digital resources, then, the particular challenge is to build unified service delivery models for both on-site and remote service that rely on common service providers and training programs, collaborative approaches to service, tools for collaborative service delivery, and a shared set of service values.

What might be some approaches to information service that integrate reference with technology support, are available at all times, make use of existing customer service technologies, and can be accessed from a variety of locations and through multiple communication modes?

A student studying at home navigates the Web, looking for information related to a paper due the next day. She intuitively moves through clustered subject fields before settling on a gateway for a topic that captures her imagination. Along the way she has worked closely with a subject expert who advised her as she invoked electronic user aids, selected information resources, and sought scholarly information on Web sites. At a recommended gateway, she finds links to an ample number of electronic information resources, guides developed by subject experts, additional links to Web sites, full-text documents, descriptions of printed resources, and entry points for a variety of additional services and resources that expedite her research.

From a workstation in the library, a student launches a metasearch engine that simultaneously searches online catalogs for printed materials, local digital library holdings, and scholarly resources on the Internet. After constructing a search strategy with the assistance of a librarian with whom he just met, he sets a series of parameters for his search that defines the resources to be queried and the type of information sources expected. The results of the search aggregate by document type, location, and format, and each gathering includes instructions for locating or ordering delivery of the items. He decides to retrieve the printed books and articles a bit later and begins to download some of the documents found on the Web. A nearby consultant assists him in formatting and storing the information for later use.

An information specialist sits at a computer workstation in the customer support center. The workstation receives and queues incoming email, chat, telephone, and video modes of requesting information and services from workstations in a variety of locations- homes and offices, information kiosks around campus and in residence halls, and public service areas. Transactions include ready-reference questions to which he responds immediately with a combination of electronic and print resources at hand; indepth reference questions that he forwards to subject specialists on call; network support service requests that he enters into the customer support system; and requests for consultations that he books on experts' electronic calendars.

The social sciences librarian leaves the office of a sociologist with whom she just consulted on some journal subscriptions and electronic book purchases. Returning to her office down the hall in the social sciences building, she is just in time to begin her shift as the on-call social sciences expert. A short time into her shift, while working on a web-based gateway to information resources and services for a field within her responsibility area, she 
notices on her calendar that an appointment has been made for a student during her office hour later that day. She then receives her first reference question of the day, routed to her from the customer support center.

These vignettes are not science fiction. The technologies and services described are currently available in other service settings and are well within the reach of academic librarians. To understand how others are meeting these challenges, one need only place a telephone order with a major retail service provider at 2 a.m. or visit the Land's End Web site, where real-time personal assistance is available around the clock for selecting and ordering a desired product even while navigating its Web pages. ${ }^{14}$

All the components are readily at hand: twenty-four-hour libraries, technology help desks with interactive and other customer-support capabilities, in- creasingly rich electronic information collections, sophisticated document delivery systems, electronic reserves, evermore-powerful intelligent agents and search engines, and the commitment and values of reference providers determined to realize the full potential of these new technologies and environments. Only our imaginations and perceived organizational constraints prevent us from bringing them together in stimulating new combinations for our students, faculty, and staff.

The next generation of information service must not only advance the notion of integrated information service both on-site and remote, but it also must recognize elements common to both and be supported by an organization that enables librarians and technologists to work closely together in designing systems, delivering services, allocating resources, and exploring new possibilities.

To imagine more easily how this notion of integrated information service

\section{TABLE 1}

\section{On-site/Remote Service Matrix}

\begin{tabular}{|c|c|c|c|}
\hline & $\begin{array}{l}\text { Services Available } \\
\text { on Premises }\end{array}$ & $\begin{array}{l}\text { Services Available } \\
\text { to Remote Users }\end{array}$ & Staffing \\
\hline $\begin{array}{l}\text { First-Tier } \\
\text { Gateway } \\
\text { Services }\end{array}$ & $\begin{array}{l}\text { Basic use and finding } \\
\text { questions related to core } \\
\text { information resources, } \\
\text { supported software, and } \\
\text { hardware trouble reports }\end{array}$ & $\begin{array}{l}\text { Asynchronous user aids, } \\
\text { search engines, etc.; } \\
\text { Web service interface, } \\
\text { telephone, etc., to } \\
\text { Customer Support } \\
\text { Center }\end{array}$ & $\begin{array}{l}\text { Paraprofessionals, } \\
\text { students }\end{array}$ \\
\hline $\begin{array}{l}\text { Second-Tier } \\
\text { Intermediate } \\
\text { Services }\end{array}$ & $\begin{array}{l}\text { General research } \\
\text { support and initial triage } \\
\text { of complex software or } \\
\text { hardware issues; referral } \\
\text { to experts on call or by } \\
\text { appointment }\end{array}$ & $\begin{array}{l}\text { General e-mail reference } \\
\text { and computer consult- } \\
\text { ing; general support of } \\
\text { research communities by } \\
\text { assigned liaisons; } \\
\text { referral to experts on call } \\
\text { or by appointment }\end{array}$ & $\begin{array}{l}\text { Paraprofessionals, } \\
\text { computer consultants, } \\
\text { librarians }\end{array}$ \\
\hline $\begin{array}{l}\text { Third-Tier } \\
\text { Expert and } \\
\text { Specialized } \\
\text { Services }\end{array}$ & $\begin{array}{l}\text { Subject or resource } \\
\text { experts by appointment } \\
\text { or during office hours }\end{array}$ & $\begin{array}{l}\text { Subject or resource } \\
\text { experts by appointment } \\
\text { or during office hours }\end{array}$ & $\begin{array}{l}\text { Librarians and computer } \\
\text { consultants with high- } \\
\text { level subject or instruc- } \\
\text { tional expertise }\end{array}$ \\
\hline
\end{tabular}


might map to a complex service environment and to begin to understand the possible benefits of service and organizational redesign, table 1 outlines an onsite/remote service matrix.

An important aspect of this model, beyond the integration of reference and computing support services into a comprehensive information service, is that it begins to break down conventional barriers between physical and electronic space. Both users and service providers are thus able to transition more flexibly from one to the other over time and as circumstances warrant, providing the latitude to adjust the allocation of resources according to the predilections and changing needs of library users.

To achieve this model, it is necessary to refine the concept of tiered service within all service contexts, make intermediate-level service available twenty-four hours a day, create new roles for librarians and technologists alike, and seek new organizational structures that support and encourage these directions. If successful, we will have acknowledged the convergence of information services and technologies, responded to the emergence of ubiquitous and portable computing, and found ways to bring the values of equity of access, personal service, and services tailored to the individual fully into the network in humane and scalable ways.

\section{Integrated Services On-site}

On-site information service models must fully support the entire range of contemporary user needs: information search, retrieval, and management using both print and electronic resources; communication with others (e.g., e-mail, chat, video); and the ability to shape information into reports and presentations (e.g., presentation software, productivity software, and basic multimedia development tools). These resources are typically available in computer user rooms and on personal desktop and laptop computers. As users increasingly draw on this full range of resources while working from homes, offices, user rooms, and laptops, they plug in elsewhere on campus and expect the same in libraries. The great success of the information commons concept, which typically provides a rich computing environment of this kind, is raising expectations for other venues. More efficient and effective ways of supporting all their needs on all our sites must be found.

\section{However, most libraries have yet to create electronic research environ- ments that combine information resources, asynchronous tools and instructional aids, and real-time assistance.}

Although on-site services such as circulation and reference must continue to be supported, a commitment also must be made to explore different ways of providing these services that enable their extension into the new environments that library users are entering. An integrated approach to information service that includes reference and technology support does not mean elimination of on-site, one-on-one service; but it could mean a tiered service that optimizes the use of high-level subject expertise, pooling of resources through shared service points, on-call availability of experts for both inperson and network-based service, and the freeing up of resources for increased investments in new tools and technologies that benefit all users.

An important dimension of integrated information service on-site is efficient and effective referral to the next level of expertise, when appropriate. To do this well, a service culture that views referral as a positive, rather than a negative, outcome is essential, as is a clear sense of responsibilities, competency levels, and referral thresholds. ${ }^{16}$

Another key component is a collaborative service environment wherein librarians and technologists work as peers to receive, assess, and resolve service requests. Requisites for these shared enterprises include an electronic calendaring 
system for scheduling appointments, office hours for subject experts, and customer relationship management (CRM) software. CRM software enables a customer service representative to record a service request, display a customer's service history, locate similar service requests (cases) for rapid and uniform resolution of problems, assign cases for resolution, and monitor the quality of service over time. ${ }^{17}$ Applied to the reference service environment, CRM software allows multiple service units to participate in a collaborative service, combine work flow for both on-site and remote entries to the service, achieve economies of scale by reducing redundancies and sharing expertise, obtain greater standardization in responses to common inquiries, and facilitate peer coaching and other quality assurance programs.

To sustain a successful, integrated, onsite information service, the parent organization must have full participation of library and technology personnel for staffing, training, and referrals; the ability to hire, train, and evaluate employees with minimal ambiguity in assignments, responsibility areas, and reporting lines; and calendaring, CRM, and other collaboration software.

\section{Remote Integrated Services}

These days, most libraries have worked hard to present robust collections of electronic information resources such as online catalogs, full-text databases, electronic journals, information gateways, electronic reserves, and now electronic books. Most colleges and universities also have developed collections of electronic
FIGURE 1

Information Service In-take Sources Interactive Video Telephone Electronic Mail

Information Specialists using

Electronic FAQs

Print and Electronic Reference Sources Full Array of Communications Technologies Service Protocols

Customer Relation Management Software

Information Service Delivery Modes Experts on Call

Electronic Calendars for Appointments

Telephone FAX Interactive Video CRM Service Request Tickets Electronic Mail

user aids, reference resources and search capabilities, and other user-directed resources. However, most libraries have yet to create electronic research environments that combine information resources, asynchronous tools and instructional aids, and real-time assistance. Such an environment would enable a user to obtain, even while interacting with the information resources and self-directed aids, in situ assistance of knowledgeable staff in formulating research strategies and solving navigation problems.

We are closer to realizing this ideal than may be apparent. Many of the essential tools and operational components needed in addition to those found in most academic libraries can be found in well-run technology support services on many campuses: a core service philosophy not unlike that of librarians; tiered service models that triage service re- 
quests for immediate resolution, referral to an expert, or posting to a case pool for collaborative resolution; and underlying technologies that enable collaborative approaches to problem resolution, efficient use of experts, and twenty-four-hour operation through a variety of communication modes. If what typically are several reference services at a given institution can be merged into a unified service that draws on CRM software for collaborative operation, the stage will be set for integrating reference with the technology help service and creating an integrated information service that can be made available through the network as well as on-site.

The remaining critical component for such a service is the Internet call center, which integrates telephone, e-mail, chat, video, and other inputs into a single incoming queue within a powerful workstation (see figure 1). An information specialist can employ FAQs, voice-recognition database queries, a ready reference collection at hand, electronic reference and other information resources, accumulated service histories within a CRM system, and a variety of service protocols (hardware, software, reference) in directly resolving queries, referring to experts on call, or making appointments with experts.

The Internet call center thus anchors an integrated, real-time information service for remote users in much the same way that a library's information desk serves as the point of departure for various services at multiple levels of need. As the intermediate-level entry point for Web, telephone, and other remote inputs, the center can operate around the clock to immediately resolve low- and intermediate-level questions and problems while facilitating access to expert assistance at a later, mutually convenient time. ${ }^{18}$

To achieve this degree of integrated information service for remote users, the parent organization must have rich access to, and routine participation of, staff proficient in automatic call distribution (ACD), computer-telephone integration
(CTI), CRM software, and Internet call center technologies.

\section{Getting from Here to There: Beyond Collaboration}

Common elements of on-site and remote service within an integrated information service environment present several unique opportunities. Tiered service, collaborative approaches to question/case resolution regardless of mode of entry, a common set of experts available on call and by appointment, and physical and electronic information desks are the common elements. These in turn provide the

Creating a service environment that fully meets the information service needs of academic library users has not been easy so far and likely will not be any easier here on out. By definition, transformation almost never is.

opportunities of common hiring and training programs, cross-training and familiarization among experts, and economies of scale that allow increased flexibility in the allocation of resources for the greater and long-term good. A byproduct of these synergies, and the routine interaction of librarians and technologists, should be the ability to make more substantial investments in research and development of new services and technologies for the ultimate benefit of all users. ${ }^{19}$ In addition, new career paths become available for paraprofessionals and professionals alike.

In this integrated service environment for both on-site and remote users, our enduring service values can be reinterpreted and sustained in meaningful ways by promoting user satisfaction that derives from personal contact and by increasing the ability to verify customer satisfaction in arenas not currently monitored well. As the ability to support all users' information-seeking needs increases, including technology support, these services and service values are better represented within distance and dis- 
tributed learning environments. An enhanced ability to collaborate with other information service providers to deliver services through the network is yet another collateral benefit. ${ }^{20}$

Within so dynamic and challenging an environment, a premium must be placed on development of Web-based gateways and other electronic resources, collaboration, research and development, and alternative physical locations. Librarians can-and indeed must-explore the new roles that have been forecast for us for many years now. Generally speaking, these new roles must include the:

- integrator, who balances current expectations for on-site service with emerging demand for network-based services;

- collaborator, who transcends administrative lines and works effectively with others from and within other organizational cultures;

- colleague, who resides in an academic user community (virtually or physically) and participates in its creation, management, and distribution of information and knowledge;

- "access engineer," who develops gateways, leads research and development projects, designs search engines, and re-purposes intelligent agents; ${ }^{21}$

- leader, who facilitates change by bringing people and resources together in innovative and productive ways.

Equally important is the nature of the parent organization in which the integrated information service and librarians in these new roles are expected to prosper. The need for integrated, tiered service both on-site and remote; combined hiring, training, and evaluation of employees; a cadre of experts that includes both librarians and technologists; and the deployment and ongoing support of ACD, CTI, CRM software, and Internet call center technologies suggests the need for an organization that brings libraries, computing, and telecommunications more closely together than ever before. Carried to their logical conclusion, these needs mean a different kind of organization that embraces new and broader definitions of library, just as traditional notions of reference service are recast as a broader and more relevant information service. How difficult is it under the current circumstance to imagine customized electronic intelligent agents at the service of users and service providers alike? How difficult is it to imagine such agents arising out of the work of librarians and technologists after collaborating closely for an extended period of time while designing and delivering the next generation of information service? As Warren Bennis observed, "All of us are smarter than any of us." 22

Librarians need technologists, and vice versa. They need each other for combined strategic planning, joint research and development projects, the technology leadership now expected of all information agencies, the development of unified service interfaces, increased capacity to raise funds, and additional budget flexibility and leverage. Any number of models exists for integration of libraries and computing. California Lutheran University has successfully undertaken one of the purer forms of integration that began with considerable preplanning and redesign of jobs, organization structure, and processes. ${ }^{23}$ The University of Southern California recently initiated an integration that continues to refine what integration at a large research university means. ${ }^{24}$ And the Anderson School of Business and the university libraries at UCLA converged the school's library and information technology department to form a hybrid unit at an institution that otherwise retains separate library and computing organizations..$^{25}$ In the final analysis, it may well be that all transformational change, to paraphrase Tip $\mathrm{O}^{\prime} \mathrm{Neill}$, is local. In the end, each institution must seek its own way. ${ }^{26}$

Creating a service environment that fully meets the information service needs of academic library users has not been easy so far and likely will not be any easier here on out. By definition, transformation almost never is. So it becomes all the more important to keep one's eyes on the prize-on our users' sun, as it 
were-and to effect the changes needed to foster creative and orderly movement into the future, no matter how daunting those changes may seem now.

The game has changed. We face an array of possibilities and challenges that will leave no library un- touched. We are, whether we want to or not, about to become much more than we are now-or much less. How we respond to the challenges and take advantage of the opportunities will define our role in modern society for some time to come. ${ }^{27}$

\section{Notes}

1. Jerry D. Campbell, "Shaking the Conceptual Foundations of Reference: A Perspective," Reference Services Review 20 (1992): 29-35. Campbell in turn has been the keynote speaker in a series of "Rethinking Reference Institutes" conducted by Ann Lipow through her Library Solutions Institute beginning in 1993.

2. James Govan, "Ascent or Decline? Some Thoughts on the Future of Academic Libraries," in The Future of the Academic Library. Proceedings of the Conference Held at the University of Wisconsin, September 1989, ed. E. P. Trani (Champaign, Ill.: Graduate School of Library and Information Science, Univ. of Illinois, 1989), 24-44.

3. Steve Coffman and Matthew L. Saxton, "Staffing the Reference Desk in the Largely Digital Library," Reference Librarian 66 (1999): 159-60.

4. Surveys of these efforts are available in Bernie Sloan, "Service Perspectives for the Digital Library: Remote Reference Services," available from http://www.lis.uiuc.edu/ b-sloan/eref.html [April 2000]; Chris D. Ferguson and Charles A. Bunge, "The Shape of Services to Come: Values-based Reference Service for the Largely Digital Library," College \& Research Libraries 58 (May 1997): 254-58, 260; and the University of Leicester's ELITE Project Site at http:// www.le.ac.uk/li/distance/eliteproject/index.htm (Apr. 2000).

5. Janice Koyama, "Http://digiref.scenarios.issues," Reference \& User Services Quarterly 38, no. 1 (1998): 51.

6. The counterpoint of Ptolemaic and Copernican cosmologies when characterizing old and new paradigms is a common device. The only other application of this metaphor to reference service that the author is aware of is Pamela Snelson, "Understanding Remote Access and Its Importance for Reference Services," in Lynne M. Stuart and Dena H. Hutto, eds., The Changing Face of Reference (Greenwich: JAI Pr., 1996), 182-83.

7. For starters, see Eli M. Noam, "Electronics and the Dim Future of the University," Science 270 (Oct. 13, 1995): 24-26; for a call to arms, see Carla J. Stoffle et al, "Choosing Our Futures," College \& Research Libraries 57 (May 1996): 213-25.

8. The average number of reference transactions among ARL members decreased 5.8 percent from $1997(201,248)$ to $1998(189,524)$ alone and a total of 10 percent from $1995(210,558)$ to 1998. The average number of circulation transactions for ARL libraries dropped 7 percent from $1996(758,944)$ to 1998 (705,872). (http:/ /www.arl.org/stats/arlstat/ [Apr. 2000]).

9. Donald Beagle, "Conceptualizing an Information Commons," Journal of Academic Librarianship 25, no. 2 (Mar. 1999): 82-89.

10. Deborah Holmes-Wong et al, "If You Build It, They Will Come: Spaces, Values, and Services in the Digital Era," Library Administration \& Management 11, no. 2 (spring 1997): 81-82.

11. Ferguson and Bunge, "The Shape of Services to Come."

12. What Bonnie A. Nardi and Vicki L. O'Day refer to in Information Ecologies: Using Technology with Heart (Cambridge, Mass.: MIT Pr., 1999) as achieving humane application and purpose by using "technology with heart" in "local habitations" (preface).

13. A point to be made more fully below is that this does not mean high-level expert assistance is available around the clock. However, it does mean that intermediate-level assistance is always available for immediate gratification issues and to schedule appointments with, and otherwise refer to, experts.

14. http://www.landsend.com/ [Apr. 2000], which enables a customer to talk on the phone with a service agent while both are navigating the Web site and to shop on the site with another customer in a different location. These features are made possible in part by Webline software (http:/ / www.webline.com). Webline also is being used in support of a collaborative, Web-based reference service under development by the Metropolitan Cooperative Library System (MCLS), a multitype library cooperative that serves more than fifty libraries in Los Angeles and Orange counties. When completed, the reference service will support remote users, operate twenty-four 
hours a day, include referrals to experts, and accommodate expansion to academic and school libraries.

15. This table, and much of the conceptualization behind it, was developed by Deborah Holmes-Wong, director of consulting services, Information Services Division, University of Southern California.

16. The literature on tiered reference service is reviewed in Soo Young Rieh, "Changing Reference Service Environment: A Review of Perspectives from Managers, Librarians, and Users," Journal of Academic Librarianship 25, no. 3 (May 1999): 179.

17. Clarify, a popular CRM system, is currently being used by the USC Customer Support Center, an information technology help desk, for IT service request intake, report tracking, and service delivery. USC librarians are experimenting with Clarify as a tool for collaborative reference service with the prospect of combining information and technology service support in the relatively near future. For more information on Clarify, visit http:/ /www.clarify.com [Apr. 2000].

18. A model consonant with that of Steve Coffman, "Reference as Others Do It," American Libraries 30, no. 5 (May 1999): 54-56.

19. For examples of where some of these R\&D investments might lead, see Deborah HolmesWong, "Richness vs. Reach: Using Technology to Overcome Economic Impediments to Reference Service," Reference Librarian 66 (1999): 201-11.

20. See note 14, above.

21. A term coined by Campbell, "Shaking the Conceptual Foundations."

22. Warren Bennis and Patricia W. Biederman, Organizing Genius: The Secrets of Creative Collaboration (Reading, Mass.: Addison-Wesley, 1997), frontispiece.

23. http://www.clunet.edu/iss/main.html [Apr. 2000].

24. http://www.usc.edu/isd [Apr. 2000].

25. http://www.anderson.ucla.edu/resources/acis/[Apr. 2000].

26. A theme that permeates Larry Hardesty, ed., Books, Bytes, and Bridges: Libraries and Computer Centers in Academic Institutions (Chicago: ALA, 2000). It emphasizes the variety of experience in the integration of computing and libraries while underscoring the need for such integration to arise from, and be shaped by, local values and aspirations.

27. Roy Tennant, “Determining Our Digital Destiny,” American Libraries 31, no. 1 (Jan. 2000): 55. 